\title{
A Disputa pela Terra e a Negação do Direito à Moradia: o caso da Ocupação "Aparecidinha" em Londrina/PR
}

\author{
The Land Dispute and The Right to the City: the case of the "Aparecidinha" \\ Occupation in Londrina / PR
}

\author{
La Disputa por la Tierra y el Derecho a la Ciudad: el caso de la Ocupación \\ "Aparecidinha" en Londrina / PR
}

Tatiana Monteiro Gomes ${ }^{1}$

https://orcid.org/0000-0002-6842-2440

\begin{abstract}
RESUMO: O conceito de direito à cidade, como referência teórica, é uma ferramenta importante para plataformas de reivindicação, legitimação e resistência através de movimentos e agentes sociais coletivos, ganhando relevante visibilidade e inspirando debates teóricos no campo de estudos sobre o espaço urbano e nas lutas dos movimentos sociais urbanos. Neste sentido, o direito à moradia não apenas dele faz parte, mas constitui-se em direito básico e fundamental. Dessa forma, o presente artigo tem como objetivo central analisar a disputa pela terra urbana e os obstáculos à produção do direito à cidade e à moradia, tendo como recorte empírico e espacial o caso da Ocupação "Aparecidinha", na cidade de Londrina-PR. Retomando a trajetória histórica da ocupação, procuramos identificar e compreender, a nível local, as relações de força entre diferentes agentes na produção daquele espaço, para análise das circunstâncias de realização dos direitos sociais e da resistência dos agentes sociais não hegemônicos frente às imposições dos processos de reprodução do capital no espaço. A partir das análises realizadas, observamos, entre outros aspectos, de que forma se configuram os contextos tanto de luta pelo acesso à terra urbana e à cidade, quanto de violação de tais direitos sociais a partir de determinações e dinâmicas políticas e econômicas, a diversos níveis de ação, que, ganhando diferentes nuances nos espaços da cidade, interferem diretamente na estrutura da mesma.
\end{abstract}

PALAVRAS-CHAVE: Espaço urbano. Direito à cidade. Política habitacionais. Produção capitalista do espaço. Ocupação Aparecidinha. Londrina/PR.

ABSTRACT: The concept of the right to the city, as a theoretical reference, is an important tool for claiming, legitimating and resisting platforms through movements and collective social agents, gaining relevant visibility and inspiring theoretical debates in the field of studies on urban space and in the struggles of urban social movements. In this sense, the right to housing is not only part of it, but constitutes a basic and fundamental right. Thus, the present article has the central objective of analyzing the dispute for urban land and the obstacles to the production of the right to the city and housing, having as an empirical and spatial point of view the case of the "Aparecidinha" occupation, in the city of Londrina-PR. Resuming the historical trajectory of the occupation, we seek to identify and understand, at the local level, the power relations between different agents in the production of that space, to analyze the circumstances of realization of social rights and the resistance of non-

\footnotetext{
${ }^{1}$ Mestranda em Geografia pelo Programa de Pós-Graduação em Geografia da Universidade Estadual Paulista, Campus de Presidente Prudente, na linha de Produção do Espaço Urbano. E-mail: tatiana.gomes@unesp.br.
} 
hegemonic social agents in view of the impositions of the processes reproduction of capital in space. Based on the analyzes carried out, we observe, among other aspects, how the contexts of struggle for access to urban land and the city, as well as the violation of such social rights, based on political and economic determinations and dynamics, are configured. several levels of action, which, gaining different nuances in city spaces, directly interfere in its structure.

KEYWORDS: Urban Space. Right to the city. Housing Policy. Capitalist production of space. Aparecidinha Occupation. Londrina/PR.

RESUMEN: El concepto de derecho a la ciudad, como referente teórico, es una herramienta importante para reivindicar, legitimar y resistir plataformas a través de movimientos y agentes sociales colectivos, ganando visibilidad relevante e inspirando debates teóricos em el campo de los estudios sobre el espacio urbano y em la luchas de los movimentos sociales urbanos. En este sentido, el derecho a la vivienda no solo forma parte de él, sino que constituye um derecho básico y fundamental. Así, el presente artículo tiene como objetivo central analizar la disputa por el suelo urbano y los obstáculos a la producción del derecho a la ciudad y a la vivienda, tomando como punto de vista empírico y espacial el caso de la ocupación "Aparecidinha", em la ciudad de Londrina-PR. Reanudando la trayectoria histórica de la ocupación, buscamos identificar y comprender, a nivel local, las relaciones de poder entre los diferentes agentes em la producción de esse espacio, para analizar las circunstancias de realización de los derechos sociales y la resistencia de la sociedad social no hegemónica ante las imposiciones de los procesos de reproducción del capital em el espacio. A partir de los análisis realizados, observamos, entre otros aspectos, como los contextos de lucha por el acceso al suelo urbano y a la ciudad, así como la vulneración de dichos derechos sociales, a partir de determinaciones y dinámicas políticas y económicas, se configuran de diferentes formas y niveles de actuación que, adquiriendo distintos matices em los espacios de la ciudad, interfieren diretamente em su estructura.

PALABRAS ClAVE: Espacio urbano. Derecho a la ciudad. Política de vivenda. Producción capitalista del espacio. Ocupación Aparecidinha. Londrina/PR.

\section{INTRODUÇÃO}

O processo de estruturação da cidade é uma síntese de diferentes determinações, com lógicas econômicas e práticas socioespaciais historicamente construídas e, no caso brasileiro, marcado por processos de violação do direito à cidade e à moradia para os sujeitos sociais não hegemônicos, resultando em desigualdades socioespaciais evidenciadas no espaço urbano sob o signo da exclusão e da segregação.

Tão relevante como evidenciar os processos de produção de tais desigualdades socioespaciais é adentrar em seus mecanismos, compreender as ações dos diferentes agentes e sujeitos que sobre ela interagem e suas resultantes espaciais. Dessa maneira, o objetivo central deste artigo consiste em analisar o processo de disputa pela terra urbana e pela moradia.

Os recortes espaciais adotados para a análise são, de um lado, a denominada Ocupação Aparecidinha, localizada na Zona Norte da cidade de Londrina/PR, iniciada nos anos 2000 e, de outro, a própria cidade de Londrina, considerada aqui como cidade média tal como trabalhado, dentre outros, por Abreu (2011), Amorim $(2011,2015)$ e Silva (2013). 
Conforme apontam as análises de Sposito (2011) sobre a produção do espaço urbano, as cidades médias reproduzem processos de estruturação e reestruturação semelhantes a contextos antes reservados às grandes metrópoles. No entanto, as formas como a terra urbana e os produtos imobiliários são apropriados e consumidos diferem nas duas realidades. Tratam-se de cidades que expressam, cada qual da sua maneira, a combinação de processos e escalas diferenciadas e que têm ganhado, nas últimas décadas, uma importância que merece destaque quando o objetivo é compreender o processo de urbanização brasileiro em suas múltiplas variáveis e a partir de diferentes relações sociais e espaciais.

Com a finalidade de destacar tais elementos foram retomadas a trajetória da ocupação e os contextos da formação socioespacial ao qual a ocupação em destaque está inserida. Para tanto, foi pesquisada, lida e sistematizada bibliografia sobre a cidade de Londrina, que são, entre outras, as obras de Amorim (2011), Beidack e Fresca (2011), Casaril (2009), Linardi (1995) e Silva (2006), assim como o Plano Diretor (LONDRINA, 2018) e planos locais de habitação de interesse social (LONDRINA, 2011), encontrados através dos sítios eletrônicos da Prefeitura Municipal. Para a compreensão a partir das escalas do bairro e da ocupação, foram explorados e analisados trabalhos elaborados sobre os mesmos, a partir das perspectivas de investigação escolhidas, como mostram os trabalhos de Frazão (2014), Guerra (2001), Ogawa (2014) e Rodrigues (2002).

Como um dos procedimentos metodológicos para o desenvolvimento deste artigo, também foram realizados dois trabalhos de campo, possibilitados através da colaboração da Companhia de Habitação de Londrina - COHAB-LD, para interpretação da realidade construída pelos agentes sociais não hegemônicos examinados, através de observação simples, que permitiu contestações e reflexões a partir do vínculo com o objeto de estudo. As visitas a campo permitiram que se conhecesse o espaço vivido do recorte empírico escolhido para análise, através de fotos, anotações e documentos. Trata-se, portanto, de uma dupla implicação na pesquisa, a participação do pesquisador na construção do objeto de pesquisa e dos dados a serem analisados.

As cidades como condicionantes e produtos do próprio curso histórico do processo de reprodução do capital evidenciam e materializam, espacial e territorialmente, as características históricas e estruturais da trajetória do (sub)desenvolvimento capitalista brasileiro, com traços de uma formação econômica dependente. Sendo assim, o acesso privado ao espaço e a conseguinte transformação do mesmo em mercadoria de alto valor agregado engendra desigualdades, disparidades e diferenciações nas esferas políticas, econômicas e sociais, que irão se materializar em diferentes escalas espaciais. 
No entanto, o Estado, em seus diversos níveis e a partir das dinâmicas de planejamento, conduz ações coerentes ao modo capitalista de produção que trata a terra como mercadoria e, portanto, voltada aos interesses e benefícios da classe dominante e hegemônica, com tensões, ações recalcitrantes e contra movimentos. É, portanto, fundamental levar em consideração os grupos e mobilizações sociais que, movidos pela perspectiva da luta pela moradia, entram em ação a partir da falta ou limitação de políticas habitacionais ou pela impossibilidade de acesso ao mercado formal de moradias, já que os mesmos podem e devem elaborar propostas e lutar para que sejam implementadas as práticas sobre as quais nos debruçaremos a analisar neste artigo.

A fundamentação teórica elaborada para compreensão do direito à cidade como horizonte filosófico foi embasada, principalmente, nas considerações de Lefebvre (2001) que desenvolve a ideia de produção social do espaço urbano a partir da percepção de que o desenvolvimento urbano pode se estruturar de forma diferente da que se estabelece nas sociedades capitalistas, e por Harvey $(2012,2014)$ que traz para a teoria social do direito à cidade sua análise sobre o papel das cidades na transformação social a partir de contradições da urbanização e movimentos anticapitalistas.

Por fim, as principais contribuições para a construção de uma abordagem analítica sobre a luta por direitos sociais a partir de perspectivas de integração entre escalas e dimensões sócio espaço-temporais foram encontradas e sistematizadas, entre outros autores, em Scherer-Warren (2003, 2006). A elaboração da discussão sobre a violação de direitos sociais fundamentais, como o direito à cidade e à moradia está pautada nas contribuições de Santos (1987), que faz uma profunda reflexão sobre o conceito do que é ser cidadão, em uma conjuntura estrutural de crise da democracia representativa no mundo e, principalmente, no Brasil, em razão das instabilidades sociopolíticas.

Isto posto, o artigo está estruturado a partir de um primeiro item que busca destacar e discutir os elementos principais que caracterizam a lógica territorial de Londrina, retomando condições históricas da questão habitacional da mesma que contribuirão para as discussões sobre as diferentes conformações dos espaços na cidade, especialmente aqueles marcados por processos de exclusão e segregação socioespacial, como são os espaços de ocupações irregulares da terra urbana. Em seguida, busca-se retomar a historicidade e trajetória da Ocupação Aparecidinha, com a finalidade de compreender de que forma as imposições políticas e econômicas na cidade colocaram a ocupação em situação de impasse que, a nosso ver, representa, entre outros aspectos, as determinações das engrenagens capitalistas movidas por agentes econômicos e políticos para valorização e rentabilidade do espaço urbano. 
E, no último item, a partir de elementos principais do debate sobre o direito à cidade, analisamos de que forma o conjunto de elementos apresentados sobre o recorte empírico puderam determinar a mutilação da cidadania dos sujeitos sociais analisados e, por conseguinte, a violação do direito coletivo à cidade e à moradia para a ocupação Aparecidinha.

\section{O (NÃO) ACESSO À TERRA: A LÓGICA TERRITORIAL EM LONDRINA-PR}

À medida que cresce a importância do espaço para a acumulação capitalista, a reprodução e valorização do capital dependem cada vez mais do processo de produção desse espaço. Neste contexto, a cidade desempenha um papel importante na produção de riqueza acumulada em circuitos de capitais privados, antes mesmo de servir à moradia (BOTELHO, 2007). Em relação ao nosso caso de estudo, destaca-se que Londrina, desde sua fundação, orientada e comandada pela Companhia de Terras Norte do Paraná (CTNP), sob o signo de cidade mercadoria, desempenhou um forte papel atrativo para investimentos que, em conjunto à localização estratégica em relação ao entorno, permitiram um avanço dinâmico e economicamente ativo da cidade, principalmente com o sucesso da comercialização de terras pela companhia (OLIVEIRA, 2005).

A posição geográfica estratégica de Londrina reflete algumas das motivações a partir das quais a companhia fundou a cidade, pensada para atender aos interesses de agentes econômicos imobiliários através da construção da estrada de ferro, que conectaria o norte do Paraná ao Estado de São Paulo (AMORIM, 2011). Na figura 1 é possível observar a divisão administrativa do município de Londrina, e sua situação geográfica no norte do estado do Paraná e Região Sul do Brasil.

Antes mesmo de ser oficialmente fundadaem 1929, a cidade de Londrina já fazia parte de uma série de planejamentos para colonizações de cidades originadas sob o âmbito de um grande empreendimento imobiliário, movido a capital britânico através das ações da CTNP e, neste caso, a cidade já tinha sua planta pré-estabelecida e planejada para 20 mil habitantes (CASARIL, 2009).

Partindo do pressupostodefendido por Scherer-Warren (1992) de que a relação, na sociedade contemporânea, entre o uso do solo urbano e o processo de reprodução do capital tem se tornado cada vez mais estreita, conforme já apontado na introdução, a lógica territorial presente em Londrina reflete de maneira significativa esse processo.

Rapidamente, o crescimento demográfico da cidade atingiu índices que ultrapassaram as expectativas pensadas para seu plano inicial, o que implicou na necessidade de 
expansão de seu traçado e readequação das formas e usos planejados para o núcleo urbano que inaugurou a cidade (CASARIL, 2009).

Figura 1 - Londrina. Divisão administrativa e situação geográfica

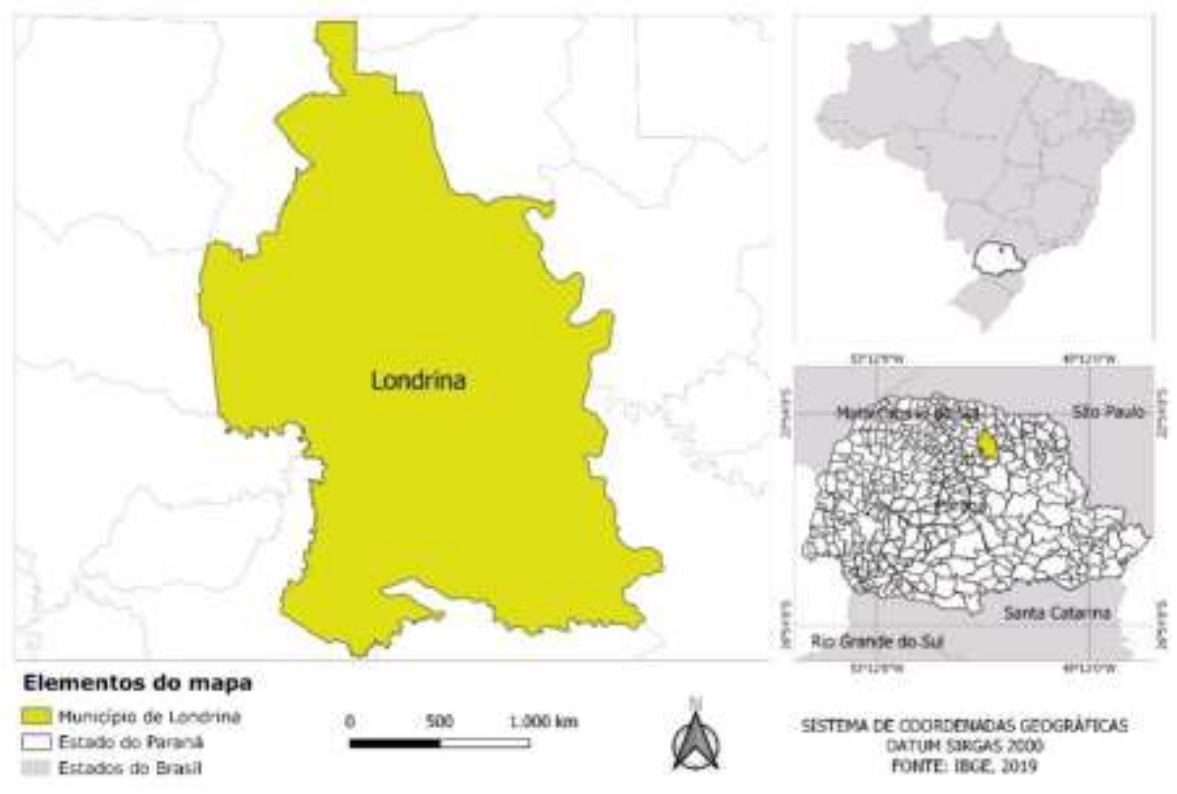

Fonte: IBGE, 2019.

No entanto, como afirma Silva (2006), foi redefinido um plano sem prévia elaboração de zoneamento para atividades funcionais da cidade e potencialmente atrelado aos interesses imobiliários e fundiários.

Desde o primeiro plano pensado para a cidade, segundo Oliveira (2005), já era possível observar as deficiências em infraestrutura em algumas áreas e a segregação induzida que refletiam, entre outros aspectos, a valorização diferencial da terra urbana, a escassez de terrenos centrais e a alta dos preços da terra.

Rapidamente, o desenvolvimento de Londrina como polo de investimento atraiu os interesses de agentes econômicos, inseridos na dinâmica imobiliária, que encontraram na produção material da cidadediferentes fontes de rendimentos. Identifica-se com isso um processo de paulatino controle privado do planejamento do espaço produzido na cidade, em consonância com a atuação do Estado (LINARDI, 1995). Dessa forma, o crescimento do tecido urbano londrinense foi demarcado por uma forte divisão socioespacial, como confirma Linardi (1995, p. 129):

[...] o projeto urbanístico de Londrina definia certa especialização das áreas, manifestando-se concomitantemente à sua criação, as primeiras evidências de segregação urbana. Ao ser implantado o plano e colocado à venda, foi estabelecida também uma distinção de valores, consequentemente, ge- 
rando uma distinção de usos e padrões, com feições de um primeiro zoneamento.

Com a criação da Companhia de Habitação de Londrina (COHAB-LD), em 1965, a expansão territorialurbana ganhou novos direcionamentos, principalmente no sentido norte. A COHAB-LD foi criada como entidade de administração indireta e com o objetivo principal de "[...] produzir e traçar diretrizes para uma política de desenvolvimento urbano e social no município" (LONDRINA, 2018). Assim, a Zona Norte de Londrina começou a ser potencialmente produzida na década de 1970, através de conjuntos habitacionais, os chamados "Cinco Conjuntos", implementados pela COHAB-LD com recursos do Banco Nacional de Habitação - o BNH (RODRIGUES, 2002).

De 1970 a 2007, 142 conjuntos habitacionais foram construídos na cidade; 44\% estavam localizados na zona norte, totalizando $56 \%$ das unidades habitacionais. Foi no período de 1978 a 1991 que a produção habitacional de interesse social ganhou maior enfoque na Zona Norte de Londrina, período auge da política federal habitacional implementada pelo BNH (BEIDACK; FRESCA, 2011). Com o desmonte do BNH em 1986 o setor de habitação passou por sérias dificuldades, refletindo em queda na construção residencial de interesse social por todo o país, inclusive em Londrina.

Fator determinante para a materialização socioespacial de processos segregadores na cidade de Londrina ocorreu a partir da valorização capitalista dos espaços produzidos por agentes econômicos atrelados à especulação imobiliária, principalmente. Os primeiros conjuntos habitacionais construídos na Zona Norte eram destinados para a população de baixo poder aquisitivo. No entanto, com a implantação de infraestruturas como a pavimentação de avenidas e a construção do Hospital Dr. Anísio Figueiredo, os investimentos em diferentes setores da atividade econômica comercial e de serviços e mesmo os loteamentos da iniciativa privada provocaram forte valorização da área e o início da alteração da composição socioeconômica de seus moradores, corroborando para a exclusão dos que não conseguiam mais arcar com os elevados custos de moradia (BEIDACK; FRESCA, 2011).

A implantação de loteamentos na Zona Norte ultrapassou as demais porções da cidade, demonstrando uma atuação intensa e efetiva de diferentes agentes na produção do espaço, desde empresas loteadoras, construtoras, imobiliárias, proprietários fundiários, até pessoas físicas. Essa área da cidade passou a ser atrativa para investimentos de uma fração do capital representada por agentes econômicos à procura de apropriação de renda e reprodução do capital, através de futura valorização.

No mesmo ritmo desta produção considerada aqui como hegemônica, os dados da COHAB-LD (LONDRINA, 2017) traziam à luz a situação de ocupações na cidade de 
Londrina: 68 áreas ocupadas de forma irregular que abrigavam, aproximadamente, 3,8 mil famílias, chegando a um total de 10.867 pessoas expostas a condições precárias e de risco, o que correspondia, na época a, aproximadamente, 1,9\% do número de habitantes da cidade (IBGE, 2017). Entre essas ocupações, 22 estavam localizadas na Zona Norte de Londrina, de acordo com a Figura 2, que diferencia tais ocupações denominadas como irregulares em três tipologias: a regularizar, a remover e em área particular, caso este referente, dentre outras, à Ocupação Aparecidinha.

Figura 2 - Mapa de assentamentos precários - Londrina - PR - 2018

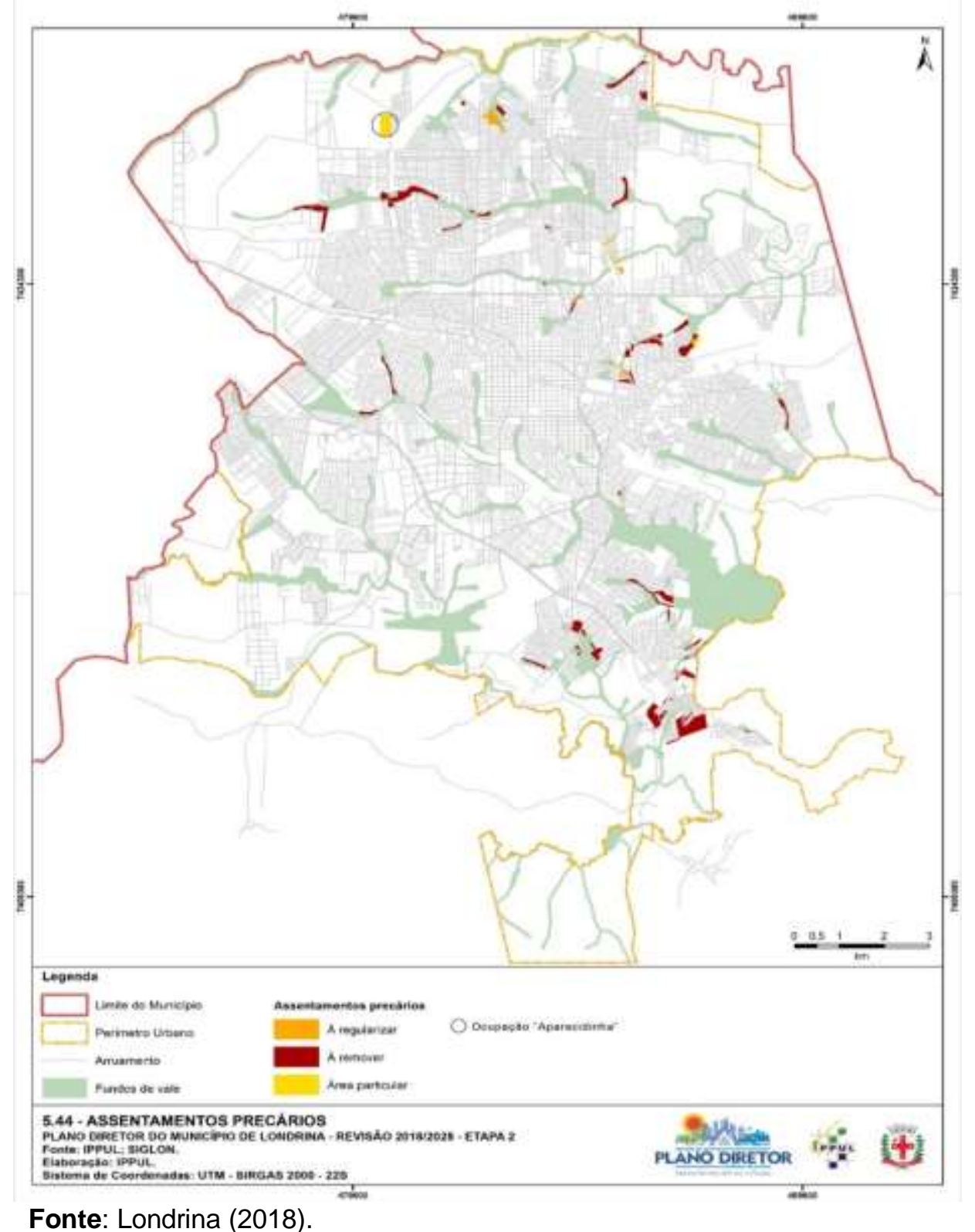

As ocupações de terras urbanas funcionam como apropriações do espaço urbano a partir de sujeitos sociais que, ao não aceitarem passivamente as condições de existência 
que Ihes são impostas, passam a se identificar de maneira potencial na determinação autônoma de como produzir ou se apropriar de um espaço do qual foram excluídos. Refletindo esse processo, a partir de 2000, as ocupações de terra urbana continuaram crescendo na cidade de Londrina. Neste ano se deu o início da formação da Ocupação "Nossa Senhora Aparecida" ou "Aparecidinha", também localizada na Zona Norte, objeto de estudo deste artigo e uma entre as demais ações de resistir e insurgir contra as alienações promovidas pela reprodução do capital.

Tanto a COHAB-LD quanto a Prefeitura Municipal de Londrina contam com instrumentos previstos pelo Estatuto da Cidade (BRASIL, 2001) voltados para regularização fundiária desse tipo de ocupação, a fim de garantir a posse de moradia a famílias que se incluem na demanda e regularizar parcelamentos e loteamentos através de assessoria jurídica. No entanto, na prática, esses objetivos não são executados ou o são de maneira pouco eficaz, principalmente por limitações do próprio Plano Diretor (LONDRINA, 2018) que deveria ser mais específico e/ou pela ausência de legislação complementar que conferisse regulamentação a princípios que aparecem apenas de maneira abstrata.

É possível observar, portanto, que a elaboração de planos e políticas habitacionais em Londrina constituiu-se, mormente, a partir da articulação entre forças políticas atuantes, atreladas a uma classe hegemônica e os conceitos técnicos adotados acabam não se materializando em sua forma plena, gerando efeitos negativos na cidade diante da mercantilização de direitos sociais fundamentais aos cidadãos, que passam a ser exclusivos daqueles que possuem condições de comprar seu direito de uso e fruição.

Houve, portanto, uma diversificação de frentes de investimentos pela cidade, refletindo, em parte, fatores de ordem macroeconômica, bem como o aparecimento de áreas alternativas àquelas já valorizadas (AMORIM, 2011). E, neste caso, o investimento em terra urbana representa um empreendimento de maior rentabilidade e valorização em tempo útil para as frações de capital envolvidas na atividade. Áreas em que antes predominavam a presença de conjuntos habitacionais, enormes vazios urbanos, ou mesmo marcadas por distâncias em relação aos meios de consumo coletivo, passam a ser alvo de inversão de capital com a abertura de novos loteamentos. E como será discutido adiante, a especulação e a valorização imobiliária têm impacto crescente sobre a violação de direitos sociais fundamentais àqueles que foram excluídos social e espacialmente da cidade e da moradia.

Compreendemos, portanto, que a avaliação de mudanças e permanências deve ser relacional, ou seja, cada parte da estrutura urbana de uma cidade deve ser analisada relativamente ao seu todo, articulando os elementos dessa mesma estrutura. A cidade é formada a partir de uma síntese de muitas determinações que compreendem desde lógicas econômicas mais abrangentes e que ganham diferentes matizes em um ou outro espaço, 
bem como por práticas espaciais que envolvem diferenças de formação, de tempo, de uso e apropriações que vão refletir na valorização imobiliária da cidade como um todo e de um espaço como elemento desta unidade.

\section{O IMPASSE DA POLÍTICA URBANA: A OCUPAÇÃO APARECIDINHA}

Maricato (1999) demonstra que,a partir de 1980, os registros passam a indicar um crescimento no número de ocupações de terra urbana pelo território brasileiro, devido, principalmente, à política de expansão da organização do Movimento Sem Terra que, após sua criação em 1984, incentivou uma série de ocupações com demandas específicas e que legitimavam a luta pelo direito à cidade, reconhecido constitucionalmente depois de 1988. A formação de ocupações, organizadas por movimentos ou ativismos sociais, promovem uma inflexão no território a partir da criação de um conflito de terra onde não existia, para solicitação de desapropriações que legitimem o direito à cidade, através da resistência que se manifesta, no caso da luta pela terra urbana, pelo "ocupar".

Contudo, ainda que as ocupações representem a legitimidade do direito à cidade como uma ferramenta de luta, também explicitam um processo de violação do mesmo como direito fundamental social básico da população pelos diferentes processos de reprodução do capital sobre o espaço. É neste contexto histórico que se insere o processo que deu origem à formação da ocupação Aparecidinha, localizada na porção norte de Londrina (figura 3).

Figura 3 - Localização da ocupação Aparecidinha em Londrina - PR

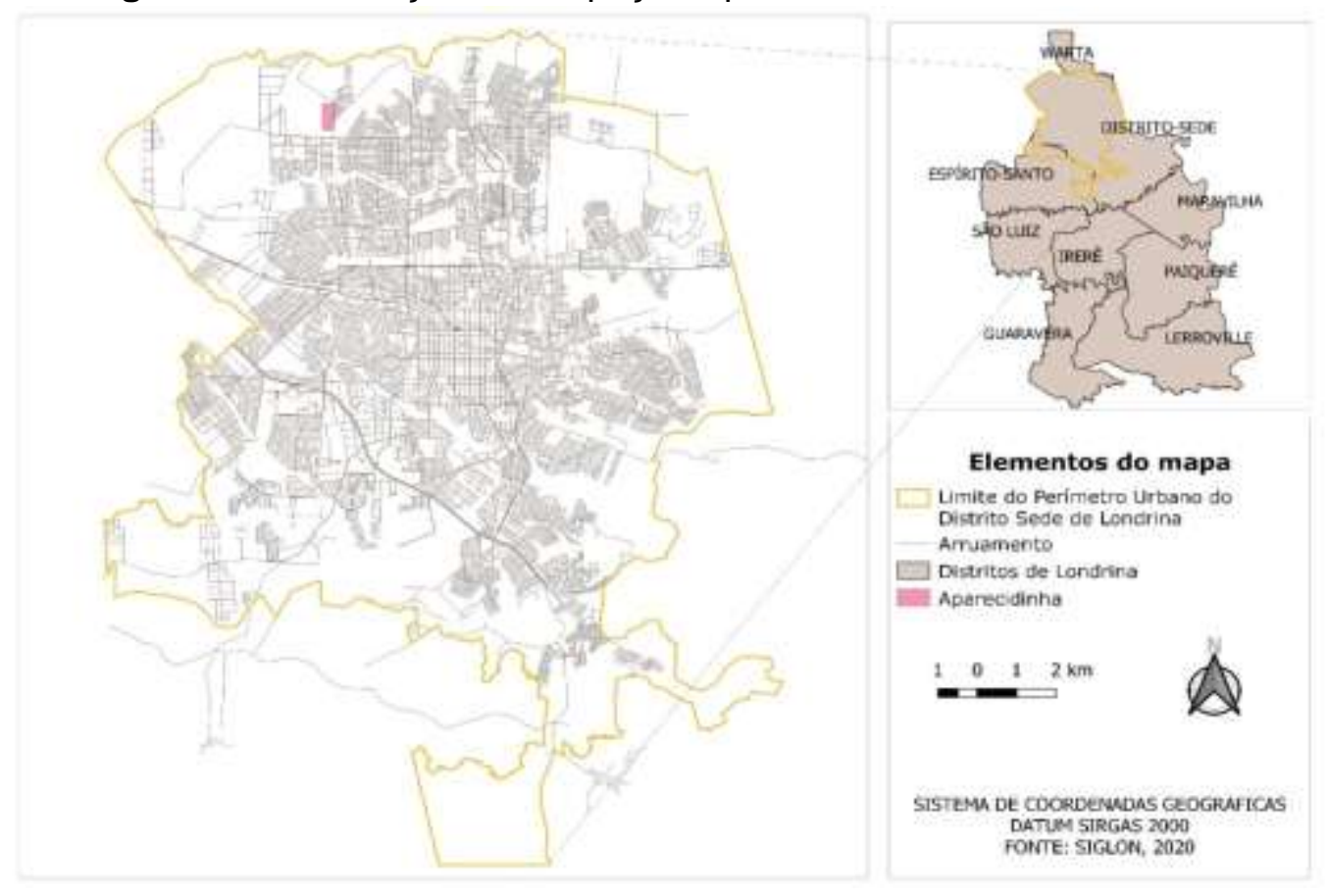

Fonte: SIGLON, 2020. 
Trata-se de um terreno particular, de 12,45 hectares, de propriedade de Gertrudes Ellwein (LONDRINA, 1995). Sua ocupação foi iniciada no ano de 2000, quando cerca de 30 famílias chegaram ao local, a partir de uma demanda específica por moradia e assistidas pela Federação dos Moradores de Assentamento e Sem-Teto de Londrina, a FASTEL (GUERRA, 2001). Em menos de três dias o número de famílias ocupando o local chegava a 280. A origem dessa mobilização se deu através de amigos e familiares dos ocupantes que eram moradores, principalmente, do Jardim São Jorge, bairro que faz divisa com o terreno ocupado e que também foi originado a partir de uma ocupação anterior que culminou na urbanização da área. Esta área pertencia ao Poder Público local e foi ocupada em 1997 por 30 famílias procedentes de ocupação anterior. Decorridos 17 anos a área foi urbanizada, dando origem ao bairro Jardim São Jorge (OGAWA, 2014). Segundo informações registradas no relatório da COHAB-LD (LONDRINA, 2017) o local estava, na época, abandonado e sem destinação de função social ou econômica por parte de sua proprietária legal.

$\mathrm{Na}$ ocasião da primeira ocupação, a proprietária entrou com pedido de reintegração de posse, deferida pela Ação Judicial nำ678/2001, em trâmite na 4ª Vara Cível da Comarca de Londrina e foi expedido o ofício à Polícia Militar do Paraná. Contudo, a mesma não foi cumprida por ausência de recursos para o desencadeamento da operação, conforme consta nas declarações do processo judicial em trâmite.

O imóvel teria sido desocupado em razão de um programa mobilizado pela COHABLD, para provimento de habitação aos moradores do terreno. O local passou a ser alvo de intervenção do Programa de Urbanização, Regularização e Integração de Assentamentos Precários - Projeto FNHIS 2009, da COHAB-LD, que previa a construção de unidades habitacionais, através de recursos federais, para atendimento das famílias que residiam na área. Concluído o processo técnico previsto pelo Programa, as famílias residentes do local, em 2012, foram realocadas para o empreendimento Jardim Horizonte II (também localizado na área norte de Londrina), com residências geminadas e com uso de cada terreno repartido entre duas famílias.

Segundo Frazão (2014) o terreno permaneceu desocupado de 2012 a 2014, e neste período não recebeu nenhum tipo de manutenção ou destinação à função social por parte da proprietária, mantendo resquícios das ocupações anteriores. Dessa forma, em janeiro de 2014 o terreno foi novamente ocupado por um novo grupo de famílias, de origens diversas: desde familiares e amigos dos ocupantes anteriores ou dos moradores do bairro São Jorge até pessoas que chegaram de cidades vizinhas. 
Considerando o caráter público atribuído ao processo judicial, em articulação com a 9a Vara Cível de Londrina - Poder Judiciário de Estado do Paraná, foi possível ter acesso às partes inerentes ao mesmo (Processo no 0003776-57.2014.8.16.0014 de 21 de janeiro 2014) e compreender a situação judicial em que se encontra a ocupação. Em 23 de janeiro de 2014, Toni Karan, então genro da falecida proprietária, ingressou com ação de reintegração de posse alegando que "[...] pessoas desconhecidas haviam tomado posse da área particular rural de forma clandestina, com a finalidade de protestar contra atrasos na concessão de financiamentos do programa Minha Casa, Minha Vida" (PARANÁ, 2014, p. 188).

Conforme o texto referente ao processo, o pedido foi indeferido pela insuficiência de requisitos estipulados pelo Código de Processo Civil, ou seja, o demandante não conseguiu juntar um corpo probatório que demonstrasse a detenção da posse do bem. Primeiramente, não havia título de propriedade em nome de "Toni Karan", nem documento algum que conferisse posse ou administração do bem, assim como nenhuma comprovação do parentesco com a proprietária legal, Gertrudes Ellwein.

Toni Karan ainda apresentou alguns documentos que, conforme decisão judicial, também careciam de eficácia probatória por se tratar de documentos unilaterais. Em 17 de fevereiro de 2014 o autor desistiu da ação e o processo foi arquivado em 05 de março de 2014 (PARANÁ, 2014). Entre tais documentos apresentados, estavam negociações com imobiliárias e loteadoras que ocorreram nos anos de 2012 e 2013, por meio das quais o autor do processo requereu avaliações sobre o possível investimento na área ocupada em 2014.

A última, dentre as negociações verificadas no processo, foi realizada no final de 2013 com a empresa Exsa Desenvolvimento Urbano, de Indaiatuba-SP, como uma opção de venda para negócio específico de loteamento.Em formatação de parceria, a empresa estabeleceu um prazo de 60 dias para desenvolvimento do estudo e apresentação de proposta de negócio com pagamento em área construída, sendo que no período especificado não poderia haver nenhuma negociação ou venda da referida gleba, por se tratar de uma opção de exclusividade (PARANÁ, 2014).

Trata-se de informações que constituem um conjunto de fatores que demonstram o claro interesse de investimento na área, para sua valorização e rentabilidade futura. Além das negociações precedidas pelos pretensos administradores do terreno para loteamento do mesmo, existem outros planos para a área que reforçam essa conclusão, por exemplo, o projeto articulado pelo Poder Público de Londrina, para implantação, no entorno da ocupação, de uma via estrutural e um contorno rodoviário que fará ligação com a cidade de Warta (LONDRINA, 2019). 
A lógica da implantação de obras de infraestrutura também reafirma o aspecto que alimenta a especulação imobiliária/fundiária e a não democratização do acesso à terra para moradia. A especulação, neste contexto, tem o papel de promover e orientar a localização dos investimentos públicos, obedecendo à lógica de geração e captação de renda, que tem como uma de suas consequências o aumento dos preços dos terrenos e imóveis. A articulação entre os elementos apresentados e os demais que estão por detrás de todo o processo envolvendo a área norte de Londrina, refletem, sobremaneira, o paulatino controle de agentes econômicos sobre o espaço da cidade, em que a terra está constantemente colocada como centro das disputas de agentes econômicos que buscam, por meio dela, a maximização de seus rendimentos.

Portanto, identifica-se uma perda do valor simbólico da área como elemento do todo, no entanto com grande valorização imobiliária e incorporou a terra rural, às margens do perímetro urbano, em terra urbana. Com essa incorporação há a extensão do perímetro urbano sobre as glebas de terra, rapidamente repartidas em lotes urbanos. Neste caso, as engrenagens capitalistas atuam para o ganho de capital investido, que será maior com o tempo. Criam-se novas áreas de interesse para o capital, que dependem do produto a ser exigido por agentes econômicos hegemônicos.

Em janeiro de 2014, ainda, foi realizado um levantamento que estimou a existência de 240 "barracos" (termo utilizado pela COHAB-LD nos levantamentos qualitativos para designar as moradias das ocupações, sendo utilizado aqui sem nenhum sentido pejorativo), construídos ou em processo de construção. A COHAB-LD não realizou novas ações específicas junto às famílias da ocupação e as atividades de levantamento in loco foram retomadas apenas em 2017 quando foram identificadas 614 famílias (LONDRINA, 2017), o que representa o descaso do poder público em relação à questão habitacional da cidade, dificultando a interlocução com a população afetada para negociação e resolução da situação.

Conforme relatado por funcionários da COHAB-LD e pela Assistência Técnica Social de Londrina durante trabalho de campo, a origem da ocupação foi magnificada pela ação do controle notável por parte do tráfico de drogas, através de "lideranças" que se impunham pelo poder de coerção e ausência do Estado. No entanto, com o tempo, os sujeitos de controle se alteraram e nenhuma nova liderança ou organização comunitária foi reestabelecida na área (LONDRINA, 2017). As famílias, sem uma organicidade coordenada de maneira significativa, não tiveram forças para se mobilizar e pressionar o Estado para formulação de diretrizes adequadas após o início da ocupação e a partir dos entraves jurídicos impostos, elemento determinante para o impasse da política urbana no local. 
As dificuldades de legalização de ocupações variam fundamentalmente em relação à definição - de ordem política - da natureza do direito a ser reconhecido aos ocupantes. Sendo assim, nas ocupações em áreas de propriedade particular, sempre que possível, o instrumento constitucional de usucapião urbana especial é o mais indicado a ser adotado. No entanto, no caso referido, não houve uma organização substancial do poder público em articulação com os moradores para garantia desse direito antes de transcorridos cinco anos de ocupação, conforme estabelece a lei no 12.424/2011 (BRASIL, 2011). E, neste caso, por existir um entrave judicial, os moradores não tiveram mais o direito à usucapião coletiva, mesmo que o pretenso proprietário não tenha conseguido a reintegração de posse na justiça.

Mesmo que a ocupação resista até os dias de hoje, ainda não há uma previsão de resolução para garantia do direito à moradia e à cidade aos moradores do Aparecidinha, segundo a COHAB-LD (LONDRINA, 2019).

\section{CIDADANIA MUTILADA: A VIOLAÇÃO DO DIREITO À CIDADE E À MORADIA}

O conceito de direito à cidade, formulado como horizonte filosófico pelo marxista francês Henri Lefebvre em 1968, tornou-se referência teórica importante para compreensão da política urbana como uma plataforma de reivindicação e resistência através de movimentos e agentes sociais coletivos, ganhando relevante visibilidade e inspirando debates teóricos no campo de estudos sobre o espaço urbano e nas lutas dos movimentos sociais urbanos, assim como abordado por Harvey (2014) que ressalta o ressurgimento da ideia do direito à cidade atrelado ao poder e importância de tais movimentos em torno das lutas coordenadas sob a perspectiva da vida urbana cotidiana.

Lefebvre (2001) descreveu o direito à cidade através de uma leitura que pudesse encaminhar a organização socioespacial das cidades através da sobreposição do valor de uso sobre o valor de troca, ou seja, partindo do princípio de que a produção do espaço urbano não fosse reservada unicamente à lógica do mercado imobiliário.

Portanto, não se trata, unicamente, como afirma o autor, de um direito assegurado pela estrutura institucional e legislativa do Estado já que para assimilar um contexto jurídico ao conceito de direito à cidade deve-se levar em consideração a compreensão de seu verdadeiro sentido.Segundo Lefebvre (2001, p. 118) o direito à cidade:

Não pode ser concebido como um simples direito de visita ou de retorno às cidades tradicionais. Só pode ser formulado como um direito à vida urbana, transformada, renovada. Pouco importa que o tecido urbano encerre em si o campo e aquilo que sobrevive da vida camponesa conquanto que o 'urbano', lugar de encontro, prioridade 
do valor de uso, inscrição no espaço de um tempo promovido à posição de supremo bem entre os bens, encontre sua base morfológica, sua realização prático-sensível.

A compreensão do conceito de direito à cidade como um direito fundamental social difere da ideia reducionista de concepção coletiva e difusa de apenas "morar" na cidade, uma vez que sua realização se torna efetiva a partir das manifestações vitais do cidadão no contexto urbano. Segundo Harvey (2014), o direito à cidade refere-se ao direito de mudar e reinventar a cidade, tratando-se de um acesso individual e coletivo aos recursos incorporados na mesma.

A Constituição Federal de 1988 (BRASIL, 1988) aponta como ponto de partida um capítulo destinado à política urbana, através dos artigos 182 e 183. Tais artigos estabelecem alguns instrumentos capazes de oferecer ao poder público melhores condições de regular a produção e apropriação do espaço urbano através de critérios socialmente mais justos e introduz a chamada "função social da propriedade urbana". Ou seja, assim como discutido por Marshall (2002), é atribuído ao Estado, em suas diferentes frações de governo, a responsabilidade de corrigir desigualdades econômicas e dar vazão às reivindicações sociais, através de marcos jurídicos e políticas públicas.

Portanto, a redução das desigualdades e a promoção dos direitos sociais são reconhecidas constitucionalmente. No entanto, tornam-se condições preteridas dentro da agenda governamental, fortemente atrelada aos interesses de mercado, e suas consequências são negativamente perceptíveis, conforme Harvey (2014, p. 62) descreve: "[...] cada vez mais o direito à cidade vem caindo nas mãos de interesses privados ou quase privados".

O direito à cidade, como detalhado pelos diferentes planos de regulação do planejamento urbano, constitui-se majoritariamente, portanto, a partir de uma combinação entre as forças políticas atuantes e a hegemonia de uma classe econômica, aqui representada, principalmente, pelo setor imobiliário e fundiário, que acabam colaborando para a mercantilização de direitos sociais fundamentais aos cidadãos, exclusivos daqueles que possuem condições de comprar seu direito de uso e fruição. Entendendo, neste ponto, o conceito de cidadania como a garantia dos direitos sociais fundamentais ao cidadão, Marshall (2002) procurou demonstrar, através de suas reflexões, a mudança de conteúdo da cidadania a partir da emergência da produção capitalista.

Segundo Lefebvre (2001) a luta de classe tem papel importante para o resgate de direitos sociais fundamentais e para os processos de produção do espaço, produção da qual as classes e frações de classes são agentes sociais ativos. Ainda segundo o autor, "[...] a luta de classes, hoje mais que nunca, se lê no espaço" (LEFEBVRE, 2001, p. 52). Portanto, 
o autor defende que se faz necessário, através do planejamento, determinar uma estratégia urbana não hegemônica a ser implementada por grupos, classes ou frações de classes sociais, potencialmente capazes de iniciativas reivindicatórias que formulem e implementem alternativas de soluções para os problemas urbanos.

Deste modo, a pressão exercida pelas massas possui a capacidade, em determinada medida, de impelir, socialmente, o surgimento e o reconhecimento de alguns destes direitos que definem a civilização urbana e se inscrevem, constitucionalmente, na regulação das relações sociais no espaço. Nas palavras de Lefebvre (2001, p. 134):

O direito à cidade se manifesta como uma forma superior dos direitos: 0 direito à liberdade, à individualização na socialização, ao habitat e ao habitar. $\mathrm{O}$ direito à obra (à atividade participante) e o direito à apropriação (bem distinto do direito à propriedade) estão implicados no direito à cidade.

Neste mesmo sentido argumentativo, Harvey (2014, p. 15) também defende o ressurgimento do direito à cidade a partir das "[...] ruas, dos bairros, como um grito de socorro e amparo de pessoas oprimidas em tempos de desespero". O autor destaca a necessidade de organização de um movimento coletivo anticapitalista, de oposição, movido em prol da transformação da vida urbana cotidiana e da garantia de controle sobre a produção, uso e apropriação do solo urbano.

Reivindicar o direito à cidade no sentido que aqui proponho equivale a reivindicar algum tipo de poder configurador sobre os processos de urbanização, sobre o modo como nossas cidades são feitas e refeitas, e pressupõe fazê-lo de maneira radical e fundamental (HARVEY, 2014, p. 30).

Segundo Harvey (2014), a dominação dos processos de produção do espaço pela reprodução do capital pressupõe a hegemonia e controle da classe capitalista sobre o processo urbano, implicando em dominação da mesma sobre os aparelhos do Estado e sobre a apropriação deste espaço. Neste sentido, o autor defende que a cidade e o processo urbano que a produz são ferramentas importantes na luta política, social e de classe. Assim, Harvey (2014) e Lefebvre (2001) concordam que o direito à cidade pode se tornar palavra de ordem na mobilização da luta anticapitalista.

No entanto, em relação ao nosso recorte empírico, é possível perceber uma violação irrestrita dos direitos à cidade e à moradia que deveriam pressupor ferramentas básicas de luta pela legitimidade e resistência dos sujeitos sociais envolvidos.

Os elementos apresentados nos permitem observar que não faltam esforços do aparelho de Estado em consonância com agentes econômicos privados para limitar cada vez mais a fruição de direitos e exercício da cidadania pelos moradores do Aparecidinha. 
Neste sentido, concordamos com as ideias propostas por Santos (1987) sobre a garantia das condições de reprodução do capital por forças políticas e privadas as custas de direitos políticos, individuais e coletivos, para manter a pobreza de milhões de brasileiros que, em algum momento, acreditaram no modelo econômico. E, a nosso ver, da mesma maneira que a sobrevivência da reprodução e valorização capitalista se dá, entre outros aspectos, através do espaço, é também através do espaço que a cidadania se dá tal como ela é hoje, ou seja, de maneira incompleta e violada.

Para Santos (1987), ainda que a cidadania seja uma prerrogativa da sociedade que atinge a todos, é cotidianamente ameaçada por um sistema implacável, pois não se basta através de uma declaração de intenções, quando a mesma apresenta limites como uma situação social, jurídica e política.

\section{CONSIDERAÇÕES FINAIS}

A partir da análise sobre a lógica territorial de formação de Londrina, uma cidade que já foi originada sob o signo do espaço mercadoria, foi possível identificar a evidente segregação socioespacial magnifica da em seu território, com a expulsão da população de menor poder aquisitivo para a área norte, uma porção do território londrinense que, inicialmente, não recebia investimentos em infraestruturas básicas, apresentando os terrenos de menores preços e destinada a absorver uma população que tendia ao crescimento com baixa ou nenhuma possibilidade de acesso ao mercado formal de habitação.

No entanto, com o tempo, observou-se a diversificação da frente de investimentos no local, que refletiram fatores econômicos multiescalares bem como a emergência de áreas alternativas àquelas já valorizadas, em outras porções da cidade, através do investimento e valorização da terra urbana.

Embora reflitam contextos, muitas vezes, antagônicos, ambos os fatores retratados representam significativamente a forma como a lógica territorial de gestão em uma cidade pode impactar diretamente a pobreza, exclusão socioespacial e, por conseguinte, em processos segregadores.

Como foi possível observar, um efeito de tal processo se manifesta, entre outros aspectos, através da formação das ocupações de terra urbana como reivindicação pelo direito à cidade e à moradia. As pessoas nelas envolvidas, sem acesso ao mercado formal de habitação, localizam-se onde e como podem, como uma forma de pressionar o poder público para o provimento da demanda estabelecida que, no caso do nosso recorte empírico, a Ocupação Aparecidinha, trata-se da demanda pela moradia. 
Esta, por se tratar de uma ocupação em terreno particular, faz parte de uma dinâmica que retrata ainda mais o impasse da política urbana em solucionar a questão. Este impasse está, a nosso ver, claramente esboçado através das tratativas de reintegração de posse negadas pelo poder público, ao mesmo passo em que nenhum programa de regularização da área foi proposto desde o reinício da ocupação, em 2014. Muitas podem ser as possibilidades articuladas ao caso, mas questionamos, aqui, se não se trata de uma maneira, planejada, de manter a área sobre a valorização do capital, a partir dos investimentos a serem feitos no entorno, visando maior rentabilidade futura, com um possível loteamento.

Este conjunto de elementos permite-nos afirmar que uma entre as razões pela qual o espaço vivido passa a ser marcado por enorme desigualdades e injustiças se dá pelo fato de ser um espaço, hoje, sem cidadãos efetivos. Concordamos, portanto, com Santos (1987), que a cidadania é uma condição determinante da política e anterior à economia, principalmente, no espaço. Uma alternativa, a nosso ver, para continuação deste debate perpassa pelo questionamento sobre a mudança de paradigma fundamentada em um modelo cívico de democracia deliberativa, com valorização da cidadania ativa. Um processo que, certamente, está permeado por conflitos entre diferentes culturas e espaços de cidadania conquistados de maneira coletiva.

\section{REFERÊNCIAS}

ABREU, Marlon Altavini de. Diferenciando o espaço e produzindo cidades: Lógicas e agentes da produção do espaço urbano em Ribeirão Preto/SP e Londrina/PR. 2011. Dissertação (Mestrado em Geografia) - UNESP, Presidente Prudente, 2011. Disponível em: https://repositorio.unesp.br/handle/11449/123915. Acesso em: 19 ago. 2020.

AMORIM, Wagner Vinicius. A produção da habitação social de mercado nas cidades médias de Londrina/PR e Maringá/PR. Espaço Aberto, Rio de Janeiro, v. 5, n. 1, p. 95-119, 2015.

AMORIM, Wagner Vinicius. A Produção social do espaço urbanoem Londrina - Pr: a valorização imobiliária e a reestruturação urbana. 2011. Dissertação (Mestrado em Geografia) - UNESP, Presidente Prudente, 2011. Disponível em:

https://repositorio.unesp.br/handle/11449/96701. Acesso em: 16 set. 2020.

BEIDACK, Andréa Rodrigues dos Santos; FRESCA, Tânia Maria. Reestruturação urbana e novas centralidades: um estudo sobre a zona norte de Londrina - PR. Boletim de Geografia, Maringá, v. 29, n. 2, p. 147-163, 2011.

BOTELHO, Adriano. O urbano em fragmentos:a produção do espaço e da moradia pelas práticas do setor imobiliário. São Paulo: Annablume, 2007.

BRASIL. [Constituição (1988)]. Constituição da República Federativa do Brasil de 1988. Brasília, DF: Senado Federal, 1988.

BRASIL. Lei n. 10.257, de 10 de julho de 2001, que estabelece diretrizes gerais da política urbana e dá outras providências. Diário Oficial da União: seção 1, Brasília, DF, p. 1, 11 jul. 2001. Disponível em: http://www.planalto.gov.br/ccivil_03/leis/leis_2001/l10257.htm. Acesso em: 22 set. 2019. 
BRASIL. Lei 12.424 de 2011. altera a lei no 11.977, de 7 de julho de 2009, que dispõe sobre o programa minha casa, minha vida - pmcmv e a regularização fundiária de assentamento localizados em áreas urbanas, as leis nํㅗ 10.188, de 12 de fevereiro de 2001, 6.015, de 31 de dezembro de 1973, 6.766, de 19 de dezembro de 1979, e 4.591, de 16 de dezembro de 1964, 8.212, de 24 de julho de 1991, e 10.406, de 10 de janeiro de 2002 - código civil; revoga dispositivos da medida provisória $n^{\circ} 2.197-43$, de 24 de agosto de 2001; e dá outras providências. Diário Oficial da União: seção 1, Brasília, DF, p. 2, 17 jun. 2011. Disponível em: < http://www.planalto.gov.br/ccivil_03/_ato2011-2014/2011/lei/l12424.htm >. Acesso em: 22 set. 2019.

CASARIL, Carlos Cassemiro. A expansão físico-territorial da cidade de Londrina e seu processo de verticalização: 1950-2000. GEOGRAFIA (Londrina), Londrina, v. 18, n. 1, p. 65-94, 2009.

FRAZÃO, Marcelo. Assentamento "renasce" com 234 barracos. Jornal de Londrina, Londrina, 29 jan. 2014. Folha Geral, p. 7.

GUERRA, Célia. Ocupação já tem 280 famílias. Folha de Londrina, Londrina, 10 set. 2001. Folha Cidades. Disponível em: https://www.folhadelondrina.com.br/cidades/ocupacao-jatem-280-familias-358247.html. Acesso em: 26 ago. 2020.about:blank

HARVEY, David. O direito à cidade. Lutas sociais, São Paulo, n. 29, p. 73-89, 2012. HARVEY, David. Cidades rebeldes: do direito à cidade à revolução urbana. São Paulo: Martins Fontes, 2014.

IBGE. Censo demográfico de 2017. Disponível em: http://www.ibge.gov.br/home/estatistica/populacao/defaulttab_agregado.shtm. Acesso em: 15 abr. 2020.

IBGE. Limites municipais. cidades@. Rio de Janeiro: IBGE, 2019. Disponível em: https://www.ibge.gov.br/geociencias/organizacao-do-territorio/malhas-territoriais/15774malhas.html?=\&t=downloads. Acesso em: 29 ago. 2019.

LEFEBVRE, Henri. O direito à cidade. São Paulo: Centauro, 2001.

LINARDI, Maria Cecilia Nogueira. Pioneirismo e modernidade: a urbanização em Londrina - PR. 1995. Tese (Doutorado em Geografia) - Universidade de São Paulo, São Paulo, 1995.

LONDRINA. $2^{\circ}$ Registro de Imóveis. $2^{\circ}$ Ofício da Comarca de Londrina. Certidão de imóvel. Registro em: 25 jan. 1995.

LONDRINA. Prefeitura Municipal. Companhia Municipal de Habitação de Londrina. Perfil socioeconômico das famílias residentes na ocupação irregular: Nossa Senhora Aparecida/São Jorge/Bom Jesus. Londrina: COHAB-LD, 2017. Processo no 19.002.082287/2019-12.

LONDRINA. Prefeitura Municipal. Companhia Municipal de Habitação de Londrina. Plano local de habitação de interesse social. Londrina: COHAB-LD, 2011. Disponível em: http://www1 .londrina.pr.gov.br/dados/images/stories/Storage/cohab/cmhl/PLHIS/PLHISPLANO-LOCAL-DE-HABITACAO-DE-INTERESSE-SOCIAL.pdf. Acesso em: 23 jan. 2020.

LONDRINA. Prefeitura Municipal. Instituto de Pesquisa e Planejamento Urbano de Londrina - IPPUL. Plano Diretor Digital. Londrina: IPPUL, 2018. Disponível em:

http://www1.londrina.pv.gov.br/dados/images/stories/Storage/ippul/RELATORIOS/ETAPA_2CADERNO_DE_ANEXOS/PLANO_DIRETOR_DIGITAL_pdf. Acesso em: 19 out. 2019.

LONDRINA. Prefeitura Municipal. Instituto de Pesquisa e Planejamento Urbano de Londrina - IPPUL. Sistema de Informação Geográfica de Londrina (SIGLON). Londrina: IPPUL, 2019. Disponível em: http://zoneamentofacil.londrina.pr.gov.br. Acesso em: 19 nov. 2019. 
MARICATO, Erminia. A terra é um nó na sociedade brasileira... também nas cidades. Cultura Vozes, Petrópolis, v. 93, n. 6, p. 7-22, 1999.

MARSHALL, Thomas Humphrey. Cidadania e classe social: leituras sobre cidadania. Brasília: Senado Federal, 2002.

OGAWA, Vítor. São Jorge: de ocupação a bairro. Folha de Londrina, Londrina, 8 ago 2014. Folha Cidades. Disponível em: https://www.folhadelondrina.com.br/cidades/sao-jorge-deocupacao-a-bairro-889738.html. Acesso em: 26 ago. 2020.

OLIVEIRA, Edilson Luís de. A iniciativa privada e o parcelamento do solo na expansão de Londrina de 1970 a 2000. In: SIMPÓSIO INTENACIONAL CIDADES MÉDIAS: DINÂMICA ECONOMICAE PRODUÇÃO DO ESPAÇO URBANO, 1., 2005. Presidente Prudente. Anais [...]. Presidente Prudente: GAsPERR/UNESP, 2005. 1 CD-ROM.

PARANÁ. Tribunal de Justiça. (9a Vara Cível). Processo no 0003776-57.2014.8.16.0014 de 21 de janeiro 2014. Ação de reintegração de posse. Curitiba: Tribunal de Justiça, 2014.

RODRIGUES, Betânia. Cincão em festa: cinco conjuntos faz 25 anos. Folha de Londrina, Londrina, 8 dez. 2002. Caderno especial: Folha Opinião. Disponível em:

https://www.folhadelondrina.com.br/opiniao/cincao-em-festa-cinco-conjuntos-completa-25anos-427383.html. Acesso em: 23 set. 2019.

SANTOS, Milton. O Espaço do cidadão. São Paulo: Nobel, 1987.

SCHERER-WARREN, Ilse. Projetos de grande escala. A ocupação do espaço e a reação popular. Cadernos do CEAS, Salvador, n. 138, p. 51-65, 1992.

SCHERER-WARREN, Ilse. Sujeitos e movimentos conectando-se através de redes. Revista Política \& Trabalho, João Pessoa, v. 19, p. 29-37, 2003.

SCHERER-WARREN, Ilse. Das mobilizações às redes de movimentos sociais. Sociedade e Estado, Brasília, v. 21, n. 1, p. 109-130, 2006.

SIGLON - SISTEMA DE INFORMAÇÃO GEOGRÁFICA DE LONDRINA. Disponível em: http://siglon.londrina.pr.gov.br/arcgis/apps/webappviewer/index.html?id=825051b5b90e4073 9752ef474b8b67a5. Acesso em: 28 mar. 2020.

SILVA, William Ribeiro. Para além das cidades: centralidade e estruturação urbana: Londrina e Maringá. 2006. Tese (Doutorado em Geografia) - Universidade Estadual Paulista, Presidente Prudente, 2006.

SILVA, William Ribeiro. Reestruturação urbana em Londrina. Entre a expansão dos capitais locais e a incorporação e subordinação aos agentes externos. In: SPOSITO, Maria Encarnação Beltrão; ELIAS, Denise de Souza; SOARES, Beatriz Ribeiro (org.). Agentes econômicos e reestruturação urbana e regional. Campina Grande e Londrina. São Paulo: Outras Expressões, 2013. v. 1, p. 319-334.

SPOSITO, Maria Encarnação Beltrão. A produção do espaço urbano: escalas, diferenças e desigualdades socioespaciais. In: CARLOS, Ana Fani; SOUZA, Marcelo Lopes; SPOSITO, Maria Encarnação Beltrão (org.). A produção do espaço urbano: agentes e processos, escalas e desafios. São Paulo: Contexto, 2011. p. 123-145.

Recebido: novembro de 2020. Aceito: abril de 2021. 